\title{
Tobacco Health Risk Awareness among Socially Disadvantaged People-A Crucial Tool for Smoking Cessation
}

\author{
Marek Milcarz ${ }^{1}$, Kinga Polanska ${ }^{1, *}$, Leokadia Bak-Romaniszyn ${ }^{2}$ and Dorota Kaleta ${ }^{1}$ \\ 1 Department of Hygiene and Epidemiology, Medical University of Lodz, 90-647 Lodz, Poland; \\ marek.milcarz@op.pl (M.M.); dkaleta@op.pl (D.K.) \\ 2 Department of Nutrition in Digestive Tract Diseases, Medical University of Lodz, 90-647 Lodz, Poland; \\ leokadia.bak-romaniszyn@umed.lodz.pl \\ * Correspondence: kinga.polanska@umed.lodz.pl; Tel.: +48-604-397-242
}

Received: 10 September 2018; Accepted: 6 October 2018; Published: 13 October 2018

\begin{abstract}
The goal of this cross-sectional survey was to assess the level of knowledge on harmful effects of environmental tobacco smoke (ETS) exposure and active smoking among sociallydisadvantaged people in Poland. The study was conducted among 1817 respondents aged 18-59 years, who used aid services from local social care institutions in Piotrkowski district. Majority of the participants were aware of the fact that smoking may cause serious diseases and lung cancer $(92 \%)$. However, those percentages were lower for awareness of ETS and health risk $(69.4 \%)$ and for awareness of smoking/ETS-associated risk of stroke and heart attack $(57 \%, 68 \%)$. The male respondents and smokers had much higher odds of lacking knowledge that smoking causes serious diseases and lung cancer compared to the females $(\mathrm{OR}=1.47$ and $\mathrm{OR}=1.86 ; p<0.05)$ and non-smokers $(\mathrm{OR}=2.35$ and $\mathrm{OR}=2.31 ; p<0.001)$. In addition, those with temporary jobs and the unemployed had a higher risk of lack of knowledge on smoking and lung cancer risk $(\mathrm{OR}=2.14$ and $\mathrm{OR}=1.66$; $p<0.05)$ as well as ETS and the risk of stroke $(\mathrm{OR}=1.52$ and $\mathrm{OR}=1.51 ; p<0.05)$ as compared to those with permanent jobs. The smokers who were aware of four health consequences of smoking indicated an intention to quit smoking within the next month more frequently when compared to those who did not have the knowledge on all of the analyzed harmful effects of tobacco use $(19.7 \%$ vs. $13.1 \% ; p<0.05)$. There is a need to improve knowledge on the dangers associated with active and passive smoking among socially disadvantaged populations.
\end{abstract}

Keywords: tobacco; active and passive smoking; health risk perception; tobacco-associated health risk awareness; socially disadvantaged populations; smoking cessation

\section{Introduction}

Socio-economic status (SES) is significantly associated with a smoking status and thus, with the smoking related morbidity and mortality [1]. Despite tobacco control measures, the rate of progress for smoking prevalence reduction has not been consistent across geographies/development status and within the countries between the groups with different SES. This indicates, as enunciated by the recent trends, that the drive to maintain the past rates of decline must not be considered obvious. Higher smoking prevalence and related health risks among socially disadvantaged groups are associated with an earlier smoking onset, heaviness of smoking and less successful quitting attempts as compared to the groups enjoying better life situations [2-5]. It needs to be stressed out that, unless action is taken to address the high prevalence of smoking among lower SES groups, we can expect a future widening of social inequalities in health. 
From the tobacco control viewpoint, one of the major applicable strategies to drive down smoking rates and environmental tobacco smoke (ETS) exposure includes dissemination of the facts concerning harmful effects of tobacco-awareness of them is frequently associated with an intention to quit and intentions predict future quitting attempts in a consistent manner [6-8]. Awareness of harmful effects of tobacco smoke also contributes to preventing the non-smokers from taking up the habit $[4,6]$. In addition, it is important because understanding the threats that active and passive smoking pose helps to introduce smoking bans at homes [5]. Finally, if smokers are aware of the influence of their smoking on others, they might be encouraged to quit.

What is important, the knowledge about harmful effects of active and passive smoking constitutes the first step to behavior modification, but it is not enough for quitting. A recent review of the perceived barriers to smoking cessation in selected vulnerable groups by Twyman et al. has described several groups of factors influencing cessation, covering individual and lifestyle issues (physical addiction, low confidence, behavioral habit, low motivation, failed past attempts, relaxation, stress and mood management, perceived mental health benefits, enjoyment, low health related knowledge), social and community barriers (lack of support from a health professional, socializing, lack of social support, high prevalence and acceptability of smoking in a community), living and working conditions (living and working circumstances, stressful situations, limited structure in a day to day life, boredom, social and geographical isolation, access to resources to quit), cultural, socio-economic and environmental factors (cultural norms, maintaining identity and socio-economic factors) [9].

Most existing studies have been focused on the impact of knowledge of harmful effects of smoking on intention to quit whereas the association between awareness/education and actual quit success has been less frequently investigated and is less clear. It also cannot be excluded that lack of awareness of health effects of smoking may be an active choice of an individual to justify his/her smoking.

The existing studies indicate that gender, age, ethnicity, education, income and smoking status are associated with awareness of harmful effects of smoking [6,8-16]. In the developed countries, majority of people are aware of the association between smoking and general health, lung cancer and heart disease [6]. However, awareness of the association between smoking and other conditions such as stroke and the impact of ETS exposure on the health of non-smokers is less frequently reported.

It needs to be emphasized that majority of the studies have been conducted among cigarette smokers (either from the general population or subgroups of people), whereas the studies among non-smokers are rarely conducted.

Given that having knowledge on the health effects of smoking is essential for behavior change, an examination of socio-economic differences in that knowledge can help to explain part of the pronounced SES differentials in smoking prevalence and cessation rates.

That was the rationale for selecting the study region (the Piotrkowski district within Lodzkie voivodship) and the study population (beneficiaries of government welfare assistance) for our analyses [17]. Piotrkowski district is a region where more than $90 \%$ of its residents are from rural areas. As evaluated by the United Nations Development Program (UNDP) the district took the 11th position among all 314 rural districts with the lowest indicators of social development in Poland. The Local Human Development Index (LHDI) (that includs Health, Education and Welfare Index) was 25.97 as compared to 39.28 for Lodzkie voivodship. In Poland the national and local institutions are responsible for administration of social aid. The right to the benefits provided under the system is given to individuals and families who are unable to cope with difficult life situations using their own empowerment, resources and abilities. In 2013, the proportion of individuals who received social aid to the overall population in Poland was $7.7 \%$. In the same year, there were 91,618 residents living on the premises of Piotrkowski District among whom 11,867 people required support of social assistance institutions. More information about the district can be found in our previous publication [17].

This study intends to assess the level of knowledge on harmful effects of smoking and ETS exposure among the socially-disadvantaged populations in Poland, and to present the relevant correlates. Those data are crucial for effective tobacco control measures among this vulnerable population. 


\section{Material and Methods}

\subsection{Study Design and Population}

Detailed characteristics of the methodology of the study have been published elsewhere [17-19]. Briefly, this cross-sectional survey was performed between October 2015 and February 2016 among people aged 18-59 years, who resided in Piotrkowski district and used aid services offered by the local welfare assistance institutions. For the purposes of this study, the poverty threshold as adopted by the social assistance institutions was used (income of no more than 634 PLN (148 Euro) for a single person monthly, and 514 PLN (120 Euro) for a family member monthly). Of 3636 individuals who met the inclusion criteria (including age and income limit) 1817 agreed in writing to participate in the study (a 49.97\% response rate). Approval was obtained from the Bioethics Committee of the Medical University in Lodz (RNN/243/15/KE) and written informed consents were collected from all the study participants.

\subsection{Questionnaire and Study Measures}

Detailed information about the questionnaire and its contents is available in previous research papers [17-19]. The adopted research tool provided for the collection of information on the respondents' socio-demographic status, including: age, gender, education, employment, subjective assessment of monthly income, subjective health state and declared health problems. In addition, data on tobacco smoking status and ETS exposure were collected. The current smokers category included: daily smokers (smoking one or more cigarettes per day over past 30 days) and the occasional smokers. The non-smoker category included never-smokers and ex-smokers. The total ETS exposure (number of hours of daily exposure to tobacco smoke at any place, including home, work and public areas) was categorized as: none, $<1 \mathrm{~h}, 1-5 \mathrm{~h}, 5-8 \mathrm{~h}$, and more than $8 \mathrm{~h}$ per day (for more details please see Milcarz et al. [17-19].

In an effort to assess the study population's awareness of the negative health consequences of active smoking, the following questions were brought up: "Does smoking tobacco cause serious illnesses?", "Does smoking tobacco cause stroke?", "Does smoking tobacco cause heart attacks?", "Does smoking tobacco cause lung cancer?". The available answers included: "yes", "no", "don't know". Affirmative responses classified the respondents as "aware", while negative and "don't know" responses classified them as "unaware".

Similarly, ETS-related health risks were investigated. The following questions were asked: "Does passive smoking cause serious illnesses?", "Does passive smoking cause stroke?", "Does passive smoking cause heart attacks?", "Does passive smoking tobacco lung cancer?". The available answers included: "yes", "no", "don't know". The respondents were categorized as "aware of the negative health consequences of ETS exposure" (for all affirmative responses), and "unaware of the negative health consequences of ETS exposure" (for all negative and "don't know" responses).

\subsection{Statistical Analysis}

For the statistical analysis the STATISTICA Windows XP version 10.0 program (StatSoft Poland Inc., Tulsa, OK, USA) was used. Statistical associations of particular characteristics categories in the analyzed subgroups were assessed using an extended version of the Mantel-Haenszel chi-squared test. The logistic regression analyses were applied to identify the risk factors for the lack of awareness of tobacco-related harm (separately for smoking-associated health risks and for ETS exposure-associated health risks). Initially, crude coefficients-ORs of the impact of odds variables on the lack of awareness of the tobacco-associated health risks were calculated. The multivariate logistic regression analysis included all of the variables significantly associated with the lack of awareness on smoking or ETS health consequences in any of the considered univariate models $(p \leq 0.05)$. Finally, the Awareness Index (AI) (aware of 0-3 negative health consequences of smoking and aware of all 4 negative health consequences smoking) in relation to the number of cigarettes smoked per day, number of previous 
quitting attempts and intention to quit smoking within the next 30 days was calculated among the smokers.

\section{Results}

\subsection{Characteristics of the Study Participants and Their Awareness of Smoking/ETS Exposure-Associated} Health Risks

The characteristics of the study sample have been also descried in details elsewhere [17]. Socio-demographic data and smoking status are presented in the Supplementary Materials-Table S1. Moreover, Table S1 displays distribution of knowledge on health effects of smoking and ETS. Majority of the participants were aware of the fact that smoking may cause serious diseases $(92.4 \%$ of the study participants, including $93.9 \%$ of the females and $89.5 \%$ of the males). That percentage was lower for awareness of ETS exposure and health risk (69.4\%). The findings also revealed that $92 \%$ of the respondents believed that smoking causes lung cancer (a lower percentage of the respondents indicated awareness of the association between ETS and lung cancer $(86.9 \%))$. However, awareness of smoking-associated risk of stroke and heart attack was particularly low, i.e., $56.9 \%, 68.5 \%$, respectively (similar percentages of the participants were noted for ETS and stroke: $56.7 \%$ as well as for ETS and heart attack: $68.4 \%)$.

\subsection{Correlates of Lack of Awareness of Smoking and ETS-Associated Health Risks}

The results of the logistic regression analyses, analyzing factors correlated with lack of awareness of smoking-associated health risks, have been presented in Table 1. The odds ratios (OR) and the 95\% confidence intervals $(\mathrm{CI})$ for lack of knowledge that smoking causes serious diseases and lung cancer showed that the male respondents had much higher odds of lacking that knowledge compared to the females (OR $=1.47 ; 95 \%$ CI: $1.02-2.11 ; p<0.05$ and OR=1.86; 95\% CI: $1.29-2.68 ; p<0.01$, respectively). In addition, compared to the non-smokers, the people who smoke were more likely not to be aware of the fact that smoking causes serious diseases and lung cancer $(\mathrm{OR}=2.35 ; 95 \% \mathrm{CI}: 1.63-3.38 ; p<0.001$ and $\mathrm{OR}=2.31 ; 95 \% \mathrm{CI}: 1.60-3.32 ; p<0.001$ respectively). Moreover, those with temporary jobs and the unemployed ones had a higher risk of lack of knowledge related to smoking and lung cancer risk as compared to those with permanent jobs (OR $=2.14 ; 95 \% \mathrm{CI}: 1.16-3.96 ; p<0.01$ and $\mathrm{OR}=1.66 ; 95 \% \mathrm{CI}$ : $1.07-2.59 ; p<0.05$, respectively).

In the case of knowledge about the fact that breathing other people's smoke in causes serious illnesses or heart attacks in non-smokers, the subjective assessment of monthly income as sufficient to cover basic needs only was associated with lower odds of lack of that awareness compared to the assessment of income as not sufficient to cover even the basic needs (OR $=0.71$; 95\% CI: 0.56-0.90; $p<0.01$ and OR $=0.76 ; 95 \%$ CI: 0.6-0.97; $p<0.05$ respectively) (Table 2). The participants with temporary jobs and the unemployed ones were less aware of the fact that passive smoking increases the risk of stroke as compared to those with permanent jobs (OR $=1.52 ; 95 \%$ CI: $1.06-2.18 ; p<0.05$ and $\mathrm{OR}=1.51 ; 95 \% \mathrm{CI}: 1.22-1.87 ; p<0.01$ respectively). Other variables in the analyses were not significantly associated with the lack of awareness of ETS-associated health risks.

The socially disadvantaged smokers who were aware of four health consequences of smoking (awareness index $(\mathrm{AI})=4$ ) indicated an intention to quit smoking within the next month more frequently than those who did not have the knowledge on any of the analyzed harmful effects of tobacco use $(\mathrm{AI}<4)(19.7 \%$ vs. $13.1 \% ; p<0.05)$ (Table 3$)$. 
Table 1. Lack of awareness of smoking-associated health risks among the study respondents $n=1817$.

\begin{tabular}{|c|c|c|c|c|c|c|c|c|}
\hline \multirow{4}{*}{ Variable } & \multicolumn{8}{|c|}{ Awareness of Smoking-Associated Health Risks } \\
\hline & \multicolumn{2}{|c|}{ Smoking Causes Serious Illnesses } & \multicolumn{2}{|c|}{ Smoking Causes Strokes } & \multicolumn{2}{|c|}{ Smoking Causes Heart Attacks } & \multicolumn{2}{|c|}{ Smoking Causes Lung Cancer } \\
\hline & Unadjusted & Adjusted & Unadjusted & Adjusted & Unadjusted & Adjusted & Unadjusted & Adjusted \\
\hline & \multicolumn{8}{|c|}{ Odds Ratio $(95 \% \mathrm{CI})$} \\
\hline \multicolumn{9}{|l|}{ Gender } \\
\hline Men & $1.79(1.26-2.54)^{* * *}$ & $1.47(1.02-2.11)^{*}$ & $1.06(0.86-1.29)$ & & $1.07(0.86-1.32)$ & & $2.21(1.57-3.11)^{* * *}$ & $1.86(1.29-2.68)^{* * *}$ \\
\hline Women & 1.00 Reference & 1.00 Reference & 1.00 Reference & & 1.00 Reference & & 1.00 Reference & 1.00 Reference \\
\hline \multicolumn{9}{|l|}{ Age (years) } \\
\hline $18-29$ & $0.86(0.39-1.89)$ & & $1.15(0.78-1.68)$ & & $1.22(0.82-1.82)$ & & $0.49(0.24-1.01) *$ & \\
\hline $30-39$ & $1.20(0.67-2.16)$ & & $0.88(0.65-1.20)$ & & $0.81(0.59-1.12)$ & & $0.56(0.34-0.92) *$ & \\
\hline $40-49$ & $1.25(0.69-2.29)$ & & $0.92(0.68-1.26)$ & & $0.93(0.67-1.29)$ & & $0.85(0.52-1.40)$ & \\
\hline $50-59$ & 1.00 Reference & & 1.00 Reference & & 1.00 Reference & & 1.00 Reference & \\
\hline \multicolumn{9}{|l|}{ Education } \\
\hline Primary & $2.86(0.87-9.41)$ & & $0.70(0.45-1.08)$ & & $1.00(0.62-1.60)$ & & $5.90(1.41-24.62) * *$ & \\
\hline Vocational & $2.99(0.91-9.77)$ & & $0.83(0.53-1.27)$ & & $0.94(0.59-1.50)$ & & $4.58(1.10-19.11)$ * & \\
\hline Secondary & $2.17(0.66-7.18)$ & & $0.92(0.60-1.42)$ & & $0.97(0.61-1.55)$ & & $2.89(0.68-12.20)$ & \\
\hline High & 1.00 Reference & & 1.00 Reference & & 1.00 Reference & & 1.00 Reference & \\
\hline \multicolumn{9}{|l|}{ Employment status } \\
\hline Permanent job & 1.00 Reference & & 1.00 Reference & & 1.00 Reference & & 1.00 Reference & 1.00 Reference \\
\hline Temporary job & $1.63(0.90-2.99)$ & & $1.12(0.78-1.60)$ & & $1.27(0.87-1.27)$ & & $2.63(1.44-4.79) * *$ & $2.14(1.16-3.96) * *$ \\
\hline Disabled or retired & $1.07(0.37-3.12)$ & & $0.83(0.46-1.51)$ & & $0.95(0.50-1.82)$ & & $2.66(1.11-6.40) *$ & $2.32(0.95-5.68)$ \\
\hline Unemployed & $1.06(0.71-1.59)$ & & $0.96(0.78-1.18)$ & & $1.08(0.86-1.36)$ & & $1.62(1.05-2.50)^{*}$ & $1.66(1.07-2.59)^{*}$ \\
\hline \multicolumn{9}{|l|}{ Subjective assessment of monthly income } \\
\hline $\begin{array}{l}\text { Sufficient to cover all living needs plus } \\
\text { may save a certain amount }\end{array}$ & $1.21(0.27-5.43)$ & & $1.32(0.53-3.24)$ & $1.32(0.53-3.24)$ & $1.63(0.65-4.10)$ & $1.63(0.65-4.10)$ & \multicolumn{2}{|c|}{-} \\
\hline Sufficient to cover all living needs & $0.65(0.32-1.29)$ & & $1.10(0.78-1.55)$ & $1.10(0.78-1.55)$ & $0.94(0.64-1.37)$ & $0.94(0.64-1.37)$ & $0.53(0.27-1.05)$ & \\
\hline Sufficient to cover basic needs only & $0.86(0.57-1.30)$ & & $1.14(0.90-1.44)$ & $1.14(0.90-1.44)$ & $1.05-(0.82-1.35)$ & $1.05(0.82-1.35)$ & $0.68(0.46-1.00)^{*}$ & \\
\hline \multirow{2}{*}{$\begin{array}{l}\text { Declined response or difficult to say } \\
\text { Not sufficient to cover even the } \\
\text { basic needs }\end{array}$} & $1.05(0.58-1.89)$ & & $1.81(1.29-2.54)^{* * *}$ & $1.81(1.29-2.54)^{* * *}$ & $1.43(1.00-2.03)^{*}$ & $1.43(1.00-2.03)^{*}$ & $1.03(0.60-1.78)$ & \\
\hline & 1.00 Reference & & 1.00 Reference & 1.00 Reference & 1.00 Reference & 1.00 Reference & 1.00 Reference & \\
\hline \multicolumn{9}{|l|}{ Smoking status } \\
\hline Smokers & $2.56(1.80-3.65)$ & $2.35(1.63-3.38)^{* * *}$ & $1.05(0.87-1.28)$ & & $1.09(0.88-1.34)$ & & $2.82(1.99-3.99) * *$ & $2.31(1.60-3.32)^{* * *}$ \\
\hline Non-smokers & 1.00 Reference & 1.00 Reference & 1.00 Reference & & 1.00 Reference & & 1.00 Reference & 1.00 Reference \\
\hline
\end{tabular}


Table 2. Lack of awareness of environmental tobacco smoke exposure-associated health risks among the study respondents $n=1817$.

\begin{tabular}{|c|c|c|c|c|c|c|c|c|}
\hline \multirow{4}{*}{ Variable } & \multicolumn{8}{|c|}{ Awareness of Environmental Tobacco Smoke Exposure-Associated Health Risks } \\
\hline & \multicolumn{2}{|c|}{ ETS Causes Serious Illnesses } & \multicolumn{2}{|c|}{ ETS Causes Strokes } & \multicolumn{2}{|c|}{ ETS Causes Heart Attacks } & \multicolumn{2}{|c|}{ ETS Causes Lung Cancer } \\
\hline & Unadjusted & Adjusted & Unadjusted & Adjusted & Unadjusted & Adjusted & Unadjusted & Adjusted \\
\hline & \multicolumn{8}{|c|}{ Odds Ratio $(95 \% \mathrm{CI})$} \\
\hline \multicolumn{9}{|l|}{ Gender } \\
\hline Men & $1.13(0.91-1.40)$ & & $1.09(0.89-1.33)$ & & $1.17(0.95-1.45)$ & & $0.95(0.71-1.28)$ & \\
\hline Women & 1.00 Reference & & 1.00 Reference & & 1.00 Reference & & 1.00 Reference & \\
\hline \multicolumn{9}{|l|}{ Age (years) } \\
\hline $18-29$ & $1.47(0.97-2.23)$ & & $1.02(0.70-1.49)$ & & $0.92(0.61-1.38)$ & & $1.34(0.74-2.41)$ & \\
\hline 30-39 & $1.31(0.94-1.82)$ & & $0.92(0.69-1.25)$ & & $0.96(0.70-1.31)$ & & $1.54(0.96-2.47)$ & \\
\hline $40-49$ & $1.22(0.87-1.72)$ & & $0.96(0.71-1.31)$ & & $1.06(0.77-1.48)$ & & $1.22(0.74-2.01)$ & \\
\hline $50-59$ & 1.00 Reference & & 1.00 Reference & & 1.00 Reference & & 1.00 Reference & \\
\hline \multicolumn{9}{|l|}{ Education } \\
\hline Primary & $0.76(0.48-1.21)$ & & $1.26(0.80-1.98)$ & & $1.00(0.80-1.25)$ & & $0.99(0.51-1.92)$ & \\
\hline Vocational & $0.70(0.44-1.11)$ & & $1.09(0.70-1.70)$ & & $1.02(0.75-1.38)$ & & $0.95(0.49-1.83)$ & \\
\hline Secondary & $0.87(0.55-1.37)$ & & $1.13(0.72-1.76)$ & & $0.87(0.64-1.18)$ & & $1.19(0.62-2.27)$ & \\
\hline High & 1.00 Reference & & 1.00 Reference & & 1.00 Reference & & 1.00 Reference & \\
\hline \multicolumn{9}{|l|}{ Employment status } \\
\hline Permanent job & 1.00 Reference & & 1.00 Reference & 1.00 Reference & 1.00 Reference & & 1.00 Reference & \\
\hline Temporary job & $1.20(0.82-1.77)$ & & $1.52(1.06-2.18) *$ & $1.52(1.06-2.18) *$ & $1.23(0.84-1.79)$ & & $0.80(0.46-1.38)$ & \\
\hline Disabled or retired & $1.71(0.96-3.03)$ & & $1.02(0.57-1.85)$ & $1.02(0.57-1.85)$ & $0.75(0.39-1.43)$ & & $0.49(0.17-1.39)$ & \\
\hline Unemployed & $1.08(0.86-1.35)$ & & $1.51(1.22-1.87)^{* * *}$ & $1.51(1.22-1.87)^{* * *}$ & $1.11(0.89-1.39)$ & & $0.91(0.67-1.23)$ & \\
\hline \multicolumn{9}{|l|}{ Subjective assessment of monthly income } \\
\hline $\begin{array}{l}\text { Sufficient to cover all living needs plus may } \\
\text { save a certain amount }\end{array}$ & $1.32(0.53-3.31)$ & $1.32(0.53-3.31)$ & & & $0.63(0.23-1.78)$ & $0.63(0.23-1.78)$ & $1.18(0.34-4.16)$ & \\
\hline Sufficient to cover all living needs & $0.86(0.60-1.23)$ & $0.86(0.60-1.23)$ & & & $0.79(0.55-1.14)$ & $0.79(0.55-1.14)$ & $1.16(0.72-1.87)$ & \\
\hline Sufficient to cover basic needs only & $0.71(0.56-0.90)$ ** & $0.71(0.56-0.90)^{* *}$ & & & $0.76(0.60-0.97)^{*}$ & $0.76(0.60-0.97) *$ & $1.05(0.75-1.46)$ & \\
\hline Declined response or difficult to say & $1.35(0.96-1.89)$ & $1.35(0.96-1.89)$ & & & $1.20(0.85-1.69)$ & $1.20(0.85-1.69)$ & $0.68(0.40-1.18)$ & \\
\hline Not sufficient to cover even the basic needs & 1.00 Reference & 1.00 Reference & 1.00 Reference & & 1.00 Reference & 1.00 Reference & 1.00 Reference & \\
\hline \multicolumn{9}{|l|}{ Smoking status } \\
\hline Smokers & $1.02(0.83-1.26)$ & & $0.99(0.81-1.20)$ & & $1.15(0.94-1.41)$ & & $0.85(0.64-1.13)$ & \\
\hline Non-smokers & 1.00 Reference & & 1.00 Reference & & 1.00 Reference & & 1.00 Reference & \\
\hline
\end{tabular}


Table 3. Awareness Index (AI) in relation to the number of cigarettes smoked daily, number of previous quitting attempts and intention to quit smoking within the next month.

\begin{tabular}{|c|c|c|c|c|c|c|c|c|c|c|}
\hline \multirow[t]{2}{*}{ Variable } & \multicolumn{2}{|c|}{$\begin{array}{c}\text { Smoking Causes Serious } \\
\text { Illness }\end{array}$} & \multicolumn{2}{|c|}{ Smoking Causes Strokes } & \multicolumn{2}{|c|}{$\begin{array}{c}\text { Smoking Causes Heart } \\
\text { Attacks }\end{array}$} & \multicolumn{2}{|c|}{$\begin{array}{c}\text { Smoking Causes Lung } \\
\text { Cancer }\end{array}$} & \multicolumn{2}{|c|}{ Awareness Index (AI) } \\
\hline & Aware & Not Aware & Aware & Not Aware & Aware & Not Aware & Aware & Not Aware & AI 0-3 & AI 4 \\
\hline $\begin{array}{c}\text { Number of cigarettes } \\
\text { smoked daily Mean }( \pm \mathrm{SD})\end{array}$ & $12.84 \pm 7.70$ & $14.65 \pm 7.37$ & $12.94 \pm 7.84$ & $13.31 \pm 7.54$ & $12.82 \pm 7.64$ & $13.70 \pm 7.85$ & $12.92 \pm 7.68$ & $13.92 \pm 7.68$ & $13.27 \pm 7.76$ & $12.95 \pm 7.70$ \\
\hline $\begin{array}{l}\text { Intention to quit smoking } \\
\text { within the next month }\end{array}$ & $105(17.4)$ & $7(9.3)$ & $76(19.3)$ & $35(13.0)$ & $82(17.5)$ & $29(14.5)$ & $7(8.4)$ & $7(8.4)$ & $39(13.1)$ & $72(19.7)^{*}$ \\
\hline $\begin{array}{l}\text { Number of previous quit } \\
\text { attempts Mean }( \pm S D)\end{array}$ & $3.13 \pm 11.22$ & $5.33 \pm 18.61$ & $3.87 \pm 13.99$ & $2.81 \pm 9.98$ & $3.55 \pm 12.79$ & $3.12 \pm 11.61$ & $3.64 \pm 13.20$ & $1.72 \pm 0.45$ & $2.73 \pm 9.57$ & $4.02 \pm 14.47$ \\
\hline
\end{tabular}




\section{Discussion}

The current study indicated that majority of the socially disadvantaged respondents were aware of the fact that smoking may cause serious diseases and lung cancer. However, those percentages were lower for awareness of ETS and health risk as well as for awareness of smoking/ETS-associated risk of stroke and heart attack. After having used socio-demographic proxy measures of vulnerability, it was demonstrated that the following population groups are less knowledgeable of tobacco's harmful effects: male, smokers, those with temporary jobs or the unemployed ones and those with the worst socio-economic status. The smokers who were aware of the four health consequences of smoking indicated an intention to quit smoking within the next month more frequently when compared to those who did not have the knowledge on all of the analyzed harmful effects of tobacco use. Our study underlined the urgent need to improve knowledge on the dangers of active and passive smoking among the socially disadvantaged populations. It provides useful data for policy makers to be considered while developing media and educational and interventional campaigns for specific population subgroups.

Similarly, as in our survey also in other studies the awareness of smoking tobacco being a cause of serious illnesses as well as the relationship between smoking tobacco and lung cancer was uniformly high [20]. Across all the countries, except for China, where the Global Adult Tobacco Survey (GATS) was conducted, more than $90 \%$ of the population indicated such knowledge [20]. In comparison, the awareness of the relationship of smoking tobacco and heart attack and stroke was much lower.

What is interesting, data from the current study indicated, similar to those observed in GATS-Poland, percentages of adults being aware of active smoking and related serious illnesses $(92.4 \%$ vs. $91.5 \%)$ and lung cancer (92.0\% vs. $92.6 \%$ ) [21]. However, much lower percentages were noted for the disadvantaged population (the current study) as compared to the representative (GATS-Poland) population for knowledge about ETS and related health risk (69.4\% vs. $81.4 \%)$, active smoking and an increased risk of stroke (56.9\% vs. $61.8 \%$ ) and heart attack (68.5\% vs. $79.9 \%)$. Thus, even bigger gaps in knowledge among this vulnerable group are indicated. As it was pointed out by Siahpush et al. of four countries (USA, UK, Australia, Canada), smokers in Canada represented the highest awareness of the smoking related risk, which authors explained by the strong anti-smoking education campaigns in Canada [1]. At the time that we have performed the survey, pictorial warnings were not present on cigarette packages. They were introduced by the Amendment of Law in 2016. Therefore, it would be interesting to evaluate if this action improved population's knowledge and perception of harmful effects of smoking.

The existing studies indicate that knowledge on the harmful effects of cigarette smoking varies by socio-demographic factors including sex, age, ethnicity, education, income and smoking status [6]. As an example, in a Bangladesh survey it has been demonstrated that women, the illiterate and residents of urban slums were less knowledgeable of tobacco's harmful effects [6]. In our study population, the men and smokers were less knowledgeable of tobacco's harmful effects as compared to the women and non-smokers. Our results are in agreement with those obtained based on GATS-Poland (women and non-smokers had a slightly higher level of knowledge about dangers of smoking) [21]. Considering gender trends, in the analysis by Gupta and Kumar there was marginally higher awareness amongst males in China and India and slightly higher awareness amongst females in Russian Federation and Ukraine [20]. That demonstrates country specific variations in harmful perception by gender. Majority of the existing studies indicate that educational attainment and income are associated with knowledge on tobacco's harmful effects $[6,8-16]$. It needs to be pointed out that our study was conducted among the people who used aid services from the local social care institutions so they mostly represented the sector with a lower educational level (only $5 \%$ of the participants had a university degree) and income (socio-economically disadvantaged persons are defined as those whose income threshold does not exceed \$158 USD (634 PLN) per month for individuals, and \$128 USD (514 PLN) per month for family members) [17-19]. That can explain the general lack of significant differences with that respect. 
Our assessments indicated that smokers who were aware of four health consequences of smoking expressed an intention to quit smoking within the next 30 days more frequently as compared to those who did not have the knowledge on all of the analyzed harmful effects of tobacco use. This is crucial information for the policy makers and institutions conducting anti-smoking interventions as by increasing a population's knowledge and awareness of smoking attributable risk the willingness to quit smoking can be stimulated. It would be also of interest to look if there is an association between awareness of health consequences of smoking and actual quit success.

It needs to be underlined that knowledge about harmful effects of active and passive smoking constitutes the first step to behavior modification, but it might be not enough for successful smoking cessation. In recent years much research has explored motivations and barriers to quitting smoking among specific disadvantaged groups including mental health patients, those living in socio-economically deprived areas and pregnant Aboriginal and Torres Strait Islander women. The following barriers to quitting smoking (in addition to the lack of knowledge) have been considered: physical addiction, poor self-efficacy, pro-smoking community norms and lack of willpower [9,22-27]. It is also hypothesized that financial stress and characteristics of smokers' social environments influence smoking cessation $[28,29]$. In addition, disadvantaged populations may have difficulty in accessing healthcare, obtaining cessation advice, and fail to receive cessation treatment during a quitting attempt. Skepticism about treatment effectiveness might also contribute to the under-administration of treatment and lack of success [30].

The following strengths of the study need to be highlighted. For the first time, knowledge on harmful effects of smoking and ETS exposure has been verified among social care beneficiaries from a rural district in Poland. In addition, rather than focusing only on tobacco smokers (as it has been done in most of the studies), this survey assessed knowledge in all the groups of people as we have expected that inaccurate awareness of tobacco's harmful effects influences users and non-users alike. In addition, we believe that awareness of ETS-related harms, which is less frequently investigated, is also crucial for effective tobacco control measures. Finally, the interviewer-administered questionnaires completed during the face-to-face interviews produced higher values of sensitivity and specificity than the self-administered questionnaires, and helped to reduce the non-response rate.

This study was also a subject to some limitations. Firstly, one limitation of the study is related to the cross-sectional study design. What is more, a possible limitation of an epidemiological study might be related to the high non-response rate. Nevertheless, the response rate in our study was $50 \%$, which is comparable to the participation rate from other questionnaire surveys in Poland. For instance the overall survey participation rate was $60 \%$ in the GATS Poland but in the Multi-Centre National Population Health Examination Survey (WOBASZ II study) the response rate was 45.5\% [21,31,32]. The recipients of social care derived from the local government records and all of the people who met eligible criteria were invited to participate. The age, gender distribution of the respondents has been checked and we have not found a statistically significant difference of the age and gender structure in the group of the respondents compared to the non-respondents group. The third limitation of the study is related to the fact that our results cannot be generalized to all the Polish population of the disadvantaged citizens, as we only researched one region in Poland (Piotrkowski district within Lodzkie voivodship - rural disadvantaged area). In addition, there was no objective validation of tobacco/ETS cigarette use. The data were based on self-report, which may be prone to response bias. However, the likelihood of response bias was assumed to be minimal since the survey was conducted so that the respondents remained anonymous. It also needs to be added that the study has evaluated different factors which might be correlated with the level of knowledge about harmful effect of smoking in order to identify important groups within this vulnerable population. However, these measures may not capture the full spectrum of the vulnerability. Finally, all the questions were asked with a negative focus. To ensure good internal validity it would be recommended to include a mixture of positive and negative statements for the participants to agree or disagree with, so as not to unintentionally direct the response. 


\section{Conclusions}

The results of our study underline the need to improve knowledge on the dangers of active and passive smoking among the disadvantaged segments of the population. There is a need to focus on some specific diseases attributed to smoking and to be aware of the fact that vulnerable groups, including male and those with the worst socio-economic status lack this knowledge.

Supplementary Materials: The following are available online at http:/ /www.mdpi.com/1660-4601/15/10/2244/s1, Table S1: Characteristics of the study respondents.

Author Contributions: M.M. conceived the original idea for the analysis, undertook the literature search, participated in the interpretation of the results, co-drafted the paper. D.K. was a Principal Investigator of the Project (grant number: (PL13-27/032/13/NMF/2015/00/2802/678), co-drafted the paper and intellectually contributed to the development of the final manuscript. K.P. participated in the interpretation of the results, co-drafted the paper. L.B.-R. co-drafted the paper. All the authors read and approved the final paper. All the authors have read and approved the final paper.

Acknowledgments: This research was funded by $\mathrm{t}$ a grant from Norway through the Norway Grants and co-financed by the Polish state budget grant number: PL13-27/032/13/NMF/2015/00/2802/678 and by the Medical University of Lodz (503/6-024-01/503-66-001). A written permission has been provided for the use of the data. The funding body had no role in the design of the study and collection, analysis, and interpretation of the data and in writing the manuscript.

Conflicts of Interest: The authors declare no conflict of interest.

\section{References}

1. Siahpush, M.; McNeill, A.; Borland, R.; Fong, G.T. Socioeconomic variations in nicotine dependence, self-efficacy, and intention to quit across four countries: Findings from the International Tobacco Control (ITC) Four Country Survey. Tob. Control. 2006, 15, iii71-5. [CrossRef] [PubMed]

2. World Health Organization. Tobacco and Inequalities. In Guidance for Addressing Inequities in Tobacco-Related Harm; World Health Organization: Geneva, Switzerland, 2014.

3. Hiscock, R.; Bauld, L.; Amos, A.; Platt, S. Smoking and socioeconomic status in England: The rise of the never smoker and the disadvantaged smoker. J. Public Health. 2012, 34, 390-396. [CrossRef] [PubMed]

4. Bryant, J.; Bonevski, B.; Paul, C. A survey of smoking prevalence and interest in quitting among social and community service organisation clients in Australia: A unique opportunity for reaching the disadvantaged. BMC Public Health 2011, 11, 827. [CrossRef] [PubMed]

5. Cavelaars, A.E.; Kunst, A.E.; Geurts, J.J.; Crialesi, R.; Grötvedt, L.; Helmert, U.; Lahelma, E.; Lundberg, O.; Matheson, J.; Mielck, A.; et al. Educational differences in smoking: International comparison. BMJ 2000, 22, 1102-1107. [CrossRef]

6. Driezen, P.; Abdullah, A.S.; Nargis, N.; Hussain, A.K.M.G.; Fong, G.T.; Thompson, M.E.; Quah, A.C.K.; Xu, S. Awareness of Tobacco-Related Health Harms among Vulnerable Populations in Bangladesh: Findings from the International Tobacco Control (ITC) Bangladesh Survey. Int. J. Environ. Res. Public Health. 2016, 13, 848. [CrossRef] [PubMed]

7. Yang, J.; Hammond, D.; Driezen, P.; Fong, G.T.; Jiang, Y. Health knowledge and perception of risks among Chinese smokers and non-smokers: Findings from the Wave 1 ITC China Survey. Tob. Control 2010, 19, i18-i23. [CrossRef] [PubMed]

8. Sansone, G.C.; Raute, L.J.; Fong, G.T.; Pednekar, M.S.; Quah, A.C.K.; Bansal-Travers, M.; Guptak, P.C.; Sinha, D.N. Knowledge of health effects and intentions to quit among smokers in India: Findings from the Tobacco Control Policy (TCP) India Pilot Survey. Int. J. Environ. Res. Public Health 2012, 9, 564-578. [CrossRef] [PubMed]

9. Twyman, L.; Bonevski, B.; Paul, C.; Bryant, J. Perceived barriers to smoking cessation in selected vulnerable groups: A systematic review of the qualitative and quantitative literature. BMJ Open 2014, 4, e006414. [CrossRef] [PubMed]

10. Raute, L.J.; Sansone, G.; Pednekar, M.S.; Fong, G.T.; Gupta, P.C.; Quah, A.C.K.; Bansal-Travers, M.; Sinha, D.N. Knowledge of health effects and intentions to quit among smokeless tobacco users in India: Findings from the International Tob Control Policy Evaluation (ITC) India Pilot Survey. Asian Pac. J. Cancer Prev. 2011, 12, 1233-1238. [PubMed] 
11. Klesges, R.C.; Somes, G.; Pascale, R.W.; Klesges, L.M.; Murphy, M.; Brown, K.; Williams, E. Knowledge and beliefs regarding the consequences of cigarette smoking and their relationships to smoking status in a biracial sample. Health Psychol. 1988, 7, 387-401. [CrossRef] [PubMed]

12. Brownson, R.C.; Jackson-Thompson, J.; Wilkerson, J.C.; Davis, J.R.; Owens, N.W.; Fisher, E.B. Demographic and socioeconomic differences in beliefs about the health effects of smoking. Am. J. Public Health 1992, 82, 99-103. [CrossRef] [PubMed]

13. Ma, G.X.; Tan, Y.; Feeley, R.M.; Thomas, P. Perceived risks of certain types of cancer and heart disease among Asian American smokers and non-smokers. J. Commun. Health 2002, 27, 233-246. [CrossRef]

14. Cummings, K.M.; Hyland, A.; Giovino, G.A.; Hastrup, J.L.; Bauer, J.E.; Bansal, M.A. Are smokers adequately informed about the health risks of smoking and medicinal nicotine? Nicotine Tob. Res. 2004, 6, S333-S340. [CrossRef] [PubMed]

15. Demaio, A.R.; Nehme, J.; Otgontuya, D.; Meyrowitsch, D.W.; Enkhtuya, P. Tobacco smoking in Mongolia: Findings of a national knowledge, attitudes and practices study. BMC Public Health 2014, 14, 213. [CrossRef] [PubMed]

16. Majmudar, P.V.; Mishra, G.A.; Kulkarni, S.V.; Rohit, D.R.; Shastri, S.S. Tobacco-related knowledge, attitides and practices among urban low socioeconomic women in Mumbai, India. Indian J. Med. Paediatr. Oncol. 2015, 36, 32-37. [PubMed]

17. Milcarz, K.; Makowiec-Dąbrowska, T.; Bak-Romaniszyn, L.; Kaleta, D. Smoking Patterns and Smoking Cessation Willingness-A Study among Beneficiaries of Government Welfare Assistance in Poland. Int. J. Environ. Res. Public Health 2017, 14, 131. [CrossRef] [PubMed]

18. Milcarz, K.; Bak-Romaniszyn, L.; Kaleta, D. Environmental Tobacco Smoke Exposure and Smoke-Free Rules in Homes among Socially-Disadvantaged Populations in Poland. Int. J. Environ. Res. Public Health 2017, 14, 447. [CrossRef] [PubMed]

19. Milcarz, M.; Polańska, K.; Bak-Romaniszyn, L.; Kaleta, D. How Social Care Beneficiaries in Poland Rate Relative Harmfulness of Various Tobacco and Nicotine-Containing Products. Int. J. Environ. Res. Public Health 2017, 14, 1029. [CrossRef] [PubMed]

20. Gupta, B.; Kumar, N. A Cross-country comparison of knowledge, attitudes and practices about tobacco use: Findings from the Global Adult Tobacco Survey. Asian Pac. J. Cancer Prev. 2014, 15, 5035-5042. [CrossRef] [PubMed]

21. Global Adult Tobacco Survey Poland 2009-2010. Available online: http://www.who.int/tobacco/surveillance/ en_tfi_gats_poland_report_2010.pdf (accessed on 8 September 2018).

22. Davis, R.; Campbell, R.; Hildon, Z.; Hobbs, L.; Michie, S. Theories of behaviour and behaviour change across the social and behavioural sciences: A scoping review. Health Psychol. Rev. 2015, 9, 323-344. [CrossRef] [PubMed]

23. Rosenthal, L.; Carroll-Scott, A.; Earnshaw, V.A.; Sackey, N.; O’Malley, S.S.; Santilli, A.; Ickovics, J.R. Targeting cessation: Understanding barriers and motivations to quitting among urban adult daily tobacco smokers. Addict. Behav. 2013, 38, 1639-1642. [CrossRef] [PubMed]

24. Baig, M.; Bakarman, M.A.; Gazzaz, Z.J.; Khabaz, M.N.; Ahmed, T.J.; Qureshi, I.A.; Hussain, M.B.; Alzahrani, A.H.; AlShehri, A.A.; Basendwah, M.A.; et al. Reasons and Motivations for Cigarette Smoking and Barriers against Quitting Among a Sample of Young People in Jeddah, Saudi Arabia. Asian Pac. J. Cancer Prev. 2016, 17, 3483-3487. [PubMed]

25. Sieminska, A.; Buczkowski, K.; Jassem, E.; Lewandowska, K.; Ucinska, R.; Chelminska, M. Patterns of motivations and ways of quitting smoking among Polish smokers: A questionnaire study. BMC Public Health 2008, 8, 274. [CrossRef] [PubMed]

26. Bryant, J.; Bonevski, B.; Paul, C.; O’Brien, J.; Oakes, W. Developing cessation interventions for the social and community service setting: A qualitative study of barriers to quitting among disadvantaged Australian smokers. BMC Public Health 2011, 11, 493. [CrossRef] [PubMed]

27. Browning, K.K.; Ferketich, A.K.; Salsberry, P.J.; Wewers, M.E. Socioeconomic disparity in provider-delivered assistance to quit smoking. Nicotine Tob. Res. 2008, 10, 55-61. [CrossRef] [PubMed]

28. Guillaumier, A.; Twyman, L.; Paul, C.; Siahpush, M.; Palazzi, K.; Bonevski, B. Financial Stress and Smoking within a Large Sample of Socially Disadvantaged Australians. Int. J. Environ. Res. Public Health. 2017, 14, 231. [CrossRef] [PubMed] 
29. Siahpush, M.; Yong, H.H.; Borland, R.; Reid, J.L.; Hammond, D. Smokers with financial stress are more likely to want to quit but less likely to try or succeed: Findings from the international tobacco control (ITC) four country survey. Addiction 2009, 104, 1382-1390. [CrossRef] [PubMed]

30. Hammett, P.J.; Fu, S.S.; Burgess, D.J.; Nelson, D.; Clothier, B.; Saul, J.E.; Nyman, J.A.; Widome, R.; Joseph, A.M. Treatment barriers among younger and older socioeconomically disadvantaged smokers. Am. J. Manag. Care 2017, 23, e295-e302. [PubMed]

31. Polakowska, M.; Kaleta, D.; Piotrowski, W.; Topór-Mądry, R.; Puch-Walczak, A.; Niklas, A.; Bielecki, W.; Kozakiewicz, K.; Pajak, A.; Tykarski, A.; et al. Tobacco smoking in Poland in the years from 2003 to 2014. Multi-centre National Population Health Examination Survey (WOBASZ). Pol. Arch. Intern. Med. 2017, 127, 91-99. [PubMed]

32. Drygas, W.; Niklas, A.; Piwońska, A.; Piotrowski, W.; Flotyńska, A.; Kwaśniewska, M.; Nadrowski, P.; Puch-Walczak, A.; Szafraniec, K.; Bielecki, W.; et al. Multi-centre National Population Health Examination Survey (WOBASZ II study): Assumptions, methods, and implementation. Pol. Heart J. 2016, 74, 681-690.

(C) 2018 by the authors. Licensee MDPI, Basel, Switzerland. This article is an open access article distributed under the terms and conditions of the Creative Commons Attribution (CC BY) license (http://creativecommons.org/licenses/by/4.0/). 